Stiff and Electrically Conductive Composites of Carbon Nanotube Aerogels and Polymers

T. F. Baumann, M. A. Worsley, J. Lewicki, S. O. Kucheyev, J. D. Kuntz, J. H. Satcher

October 19, 2011

American Chemical Society Spring Meeting San Diego, CA, United States March 25, 2012 through March 29, 2012 
This document was prepared as an account of work sponsored by an agency of the United States government. Neither the United States government nor Lawrence Livermore National Security, LLC, nor any of their employees makes any warranty, expressed or implied, or assumes any legal liability or responsibility for the accuracy, completeness, or usefulness of any information, apparatus, product, or process disclosed, or represents that its use would not infringe privately owned rights. Reference herein to any specific commercial product, process, or service by trade name, trademark, manufacturer, or otherwise does not necessarily constitute or imply its endorsement, recommendation, or favoring by the United States government or Lawrence Livermore National Security, LLC. The views and opinions of authors expressed herein do not necessarily state or reflect those of the United States government or Lawrence Livermore National Security, LLC, and shall not be used for advertising or product endorsement purposes. 


\section{STIFF AND ELECTRICALLY CONDUCTIVE COMPOSITES OF CARBON NANOTUBE AEROGELS AND POLYMERS}

Marcus A. Worsley, James Lewicki, Sergei O. Kucheyev, Joshua D. Kuntz, Joe H. Satcher, Jr. and Theodore F. Baumann

Physical and Life Sciences Directorate

Lawrence Livermore National Laboratory Livermore, CA 94551

\section{Introduction}

Carbon nanotubes (CNTs) possess a number of intrinsic properties that make them promising candidates as filler material in the design of new composite systems. CNTs can have electrical conductivities ${ }^{1}$ as high as $10^{6}$ $\mathrm{Sm}^{-1}$, thermal conductivities ${ }^{2}$ as high as $3000 \mathrm{Wm}^{-1} \mathrm{~K}^{-1}$, elastic moduli ${ }^{3}$ on the order of $1 \mathrm{TPa}$, and are extremely flexible. ${ }^{4}$ Unfortunately, the realization of these properties in macroscopic forms, such as conductive polymer/CNT composites, has been limited. ${ }^{5-17}$ In these composites, CNTs are typically dispersed throughout the polymeric matrix by addition of the individual nanotubes or bundles to precursor formulations. ${ }^{16-24}$ Since the loading levels and distribution of the CNTs in the polymer determine the conductivity of the composite, one of the challenges associated with the fabrication of conductive polymer composites is attaining uniform dispersion of the CNTs within the matrix. In addition, dispersion methods can vary greatly depending on the characteristics of matrix material. ${ }^{16-25}$ While measurable increases in electrical conductivity can be achieved through addition of as little as $0.007 \mathrm{wt} \% \mathrm{CNTs}$ to polymer matrices, ${ }^{5}$ preparation of composites with conductivities $>1 \mathrm{~S} \mathrm{~cm}^{-1}$ requires either higher loadings of CNTs $(>10 \mathrm{wt} \%)^{7-13}$ or specially-designed CNTs that facilitate dispersion in the matrix. ${ }^{25}$ Thus, the fabrication of CNTpolymer composites with conductivities on par with highly conductive semiconductors and metals for applications such as electromagnetic interference shielding can be an expensive endeavor. ${ }^{26}$ An attractive alternative to the dispersion approach for the design of conductive polymer composites would be the use of a low-density, electrically conductive CNT foam as a scaffold that can be filled or infiltrated with the polymer matrix. ${ }^{27}$ With this approach, the uniformity of the dispersed phase, and hence the conductivity of the composite, is established by the pre-formed CNT network of the scaffold. In addition, this approach could be general and utilized with a wide variety of polymer matrices.

We recently reported the synthesis of ultralow-density SWNT-based foams (SWNT-CA) with exceptional electrical and mechanical properties. ${ }^{28}$ In these foams, carbon nanoparticles were used as a binder to crosslink randomly oriented bundles of single-walled CNTs. These SWNT-CAs simultaneously exhibited increased stiffness and high electrical conductivity even at densities approaching $10 \mathrm{mg} \mathrm{cm}^{-3}$. Therefore, in addition to use as catalyst supports, sensors, and electrodes, these ultra-light and robust foams can serve as scaffolds for the preparation of novel CNT composites. As the conductive network is already established, the CNT foam can simply be impregnated through the wicking process ${ }^{29}$ with the matrix of choice, ranging from inorganic sols to polymer melts to ceramic pastes, to prepare a variety of conductive CNT composites. In this communication, we use SWNT-CA foam scaffolds for the synthesis of a highly conductive poly(dimethylsiloxane) (PDMS) composite. This polymer composite exhibits $\sim 300 \%$ increase in the elastic modulus relative to the unloaded PDMS elastomer and electrical conductivity over $1 \mathrm{Scm}^{-1}$, the highest conductivity reported for a polymer/SWNT composite at this CNT loading level (1.2 $\mathrm{wt} \%$ or $1 \mathrm{vol} \%)^{9}{ }^{9,10}$

\section{Experimental}

The SWNT-CA nanofoams, with a SWNT loading of $55 \mathrm{wt} \%(1 \mathrm{vol} \%)$ and a monolith density of $28 \mathrm{mg} / \mathrm{cc}$, were prepared as previously reported. ${ }^{28}$ Briefly, purified SWNTs were suspended in deionized water and thoroughly dispersed via sonication. Once the SWNTs were dispersed, organic sol-gel chemistry was used crosslink the CNT bundles. Typically, organic sol-gel chemistry involves the polymerization of organic precursors to produce highly crosslinked organic gels that can be dried and pyrolyzed to yield porous carbon structures. ${ }^{30}$ In this case, low concentrations of the sol-gel precursors (resorcinol, formaldehyde) and catalyst (sodium carbonate) were added to the CNT suspension to induce polymerization primarily on the walls of the CNT bundles and, more importantly, at the junctions between adjacent bundles to form an organic binder. The resulting gel was then dried and subsequently pyrolyzed to convert the organic binder to carbon, yielding the SWNT-CA nanofoam. The volume percent of SWNTs in each sample was calculated from the initial mass of SWNTs added, a CNT density of $1.3 \mathrm{~g} / \mathrm{cm}^{3}$, and the final volume of the sample. The synthesis process for the SWNT-CA allows for a range of possible shapes and sizes. In this report, SWNT-CA right cylinders with diameters of $\sim 1 \mathrm{~cm}$ and heights of $\sim 2 \mathrm{~cm}$ were fabricated. Composites were prepared by immersing the as-prepared SWNT-CA in the polymer resin prior to cure. Dow Corning Sylgard 184 was used in this work. The immersed SWNT-CA was placed under vacuum until no more air escaped from the scaffold, suggesting full infiltration of the resin. The infiltrated SWNT-CA was then cured at $60^{\circ} \mathrm{C}$ to produce the composite. The dimensions of the composite were approximately equal to those of the initial SWNT-CA.

\section{Results and Discussion}

Scanning electron microscopy (SEM) images of PDMS/SWNT-CA composites show that the SWNTs are homogenously distributed throughout the polymer matrix, suggesting that there is good wetting at the PDMS/SWNT-CA interface and that the CNT-based scaffold is intact after infiltration and curing (Figure 1). This observation is supported by the fact that the electrical conductivity of the SWNT-CA scaffold is maintained even in a fully dense insulating matrix (Table 1). To our knowledge, the conductivity of these polymer composites $\left(1 \mathrm{~S} \mathrm{~cm}^{-1}\right)$ represents the highest conductivity reported for a polymer/SWNT composite prepared at such a low CNT loading level $(1.2 \mathrm{wt} \%$ or $1 \mathrm{vol} \%))^{9,10}$ Interestingly, the electrical conductivity of this composite is on par with the highest reported value for a polymer/MWNT at a similar $\sim 1 \mathrm{wt} \%$ MWNT loading. ${ }^{25}$ As SWNTs typically contain some fraction of semiconducting tubes, as compared to MWNTs, which presumably are all metallic, one might expect a higher conductivity in the MWNT composite with similar CNT loadings. This observation highlights the need for further study in this area and suggests that even larger improvements in the conductivity of polymer composites are possible.

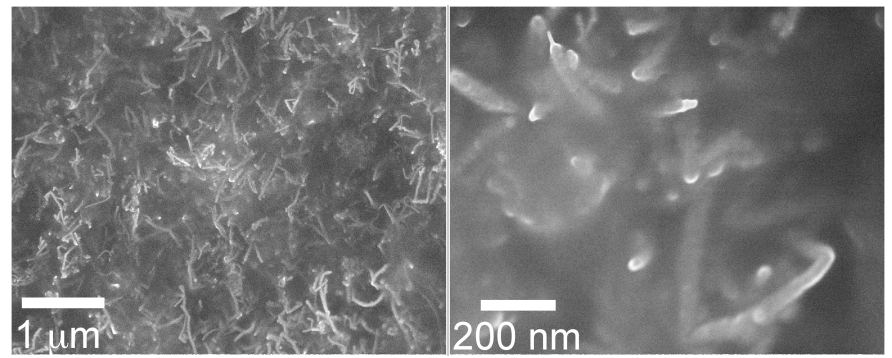

Figure 1. SEM images (under different magnifications) of conductive PDMS/SWNT-CA composites.

Table I. Physical properties of the SWNT-CA scaffold, PDMS polymer and conductive polymer composite.

\begin{tabular}{|c|c|c|c|c|}
\hline Material & $\begin{array}{c}\text { CNT } \\
\text { vol\%(wt\%) }\end{array}$ & $\begin{array}{c}\text { Density } \\
\mathrm{g} / \mathrm{cm}^{3}\end{array}$ & $\begin{array}{c}\boldsymbol{E} \\
\mathrm{MPa}\end{array}$ & $\begin{array}{c}\boldsymbol{\sigma} \\
\mathrm{S} / \mathrm{cm}\end{array}$ \\
\hline SWNT-CA & $1(55)$ & 0.028 & 1.0 & 1.12 \\
\hline PDMS & $0(0)$ & 1.04 & 4.2 & $<0.001$ \\
\hline PDMS/SWNT-CA & $1(1.3)$ & 1.01 & 14 & 1.00 \\
\hline
\end{tabular}

Nanoindentation measurements show that the PDMS/SWNT-CA experiences very elastic behavior with an $\sim 300 \%$ increase in Young's modulus as compared to the case of PDMS (Figure 2). The observed enhancement in modulus is consistent with the increase expected based on the Halpin-Tsai model for a nanotube bundle aspect ratio of $\sim 100$. $^{31}$ Similar increase in modulus was observed by Dyke et al for a PDMS/SWNT composite prepared with $1 \mathrm{wt} \%$ loading of surface-functionalized SWNT. ${ }^{20}$ 
The improved modulus is also consistent with the observation of a polymer shell that coats the CNT bundles in the SEM images. (Figure 1) The presence of the polymer shell suggests strong bonding at the PDMS/SWNT-CA interface, a key element in successful reinforcement. ${ }^{32}$ These results highlight the effectiveness of using a pre-made CNT scaffold for structural reinforcement.

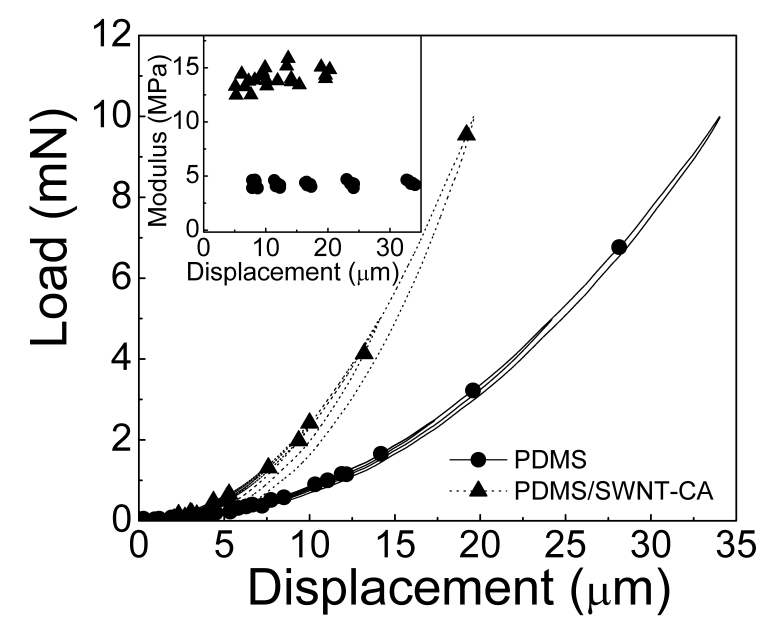

Figure 2. Partial load-displacement curves for PDMS with and without CNT-based scaffold. The inset shows depth profiles of the indentation modulus.

\section{Conclusions}

In summary, SWNT-CAs have been used as scaffolds to fabricate stiff, highly conductive polymer (PDMS) composites via the infiltration method with little to no degradation of the conductive network of the CNT-based scaffold. Conductivities as high as $1 \mathrm{Scm}^{-1}$ have been observed for SWNT loadings as low as $1 \mathrm{vol} \%(1.2 \mathrm{wt} \%)$ in polymer/SWNT-CA composites. In addition to excellent electrical conductivity, the polymer composite exhibited an $\sim 300 \%$ increase in Young's modulus, producing not only a highly conductive, but a stiffer composite as well. The exceptional properties of this polymer composite and the general nature of the fabrication method provide the potential for a whole new class of composites based on the SWNT-CA scaffold.

Acknowledgements. This work was performed under the auspices of the U.S. Department of Energy by Lawrence Livermore National Laboratory under Contract DE-AC52-07NA27344 and funded by the DOE Office of Energy Efficiency and Renewable Energy.

\section{References}

(1) Thess, A.; Lee, R.; Nikolaev, P.; Dai, H.; Petit, P.; Robert, J.; Xu, C.; Lee, Y. H.; Kim, S. G.; Rinzler, A. G.; Colbert, D. T.; Scuseria, G. E.; Tomanek, D.; Fischer, J. E. Smalley, R. E. Science 1996, 273, 483.

(2) Kim, P.; Shi, L.; Majumdar, A.; McEuen, P. L. Phys. Rev. Lett. 2001, $87,215502$.

(3) Qi, H. J.; Teo, K. B. K.; Lau, K. K. S.; Boyce, M. C.; Milne, W. I.; Robertson, J.; Gleason, K. K. J. Mech. Phys. of Solids 2003, 51, 2213.

(4) Falvo, M. R.; Clary, G. J.; Taylor, R. M.; Chi, V.; Brooks, F. P.; Washburn, S.; Superfine, R. Nature 1997, 389, 582.

(5) Bryning, M. B.; Islam, M. F.; Kikkawa, J. M.; Yodh, A. G. Adv. Mater. 2005, 17, 1186

(6) Chen, J.; Ramasubramaniam, R.; Xue, C.; Liu, H. Adv. Funct. Mater. 2006, 16, 114 .

(7) Du, F. M.; Guthy, C.; Kashiwagi, T.; Fischer, J. E.; Winey, K. I. J. Polym. Sci. Part B-Polymer Physics 2006, 44, 1513.

(8) Haggenmueller, R.; Guthy, C.; Lukes, J. R.; Fischer, J. E.; Winey, K. I. Macromolecules 2007, 40, 2417.
(9) Winey, K. I.; Kashiwagi, T.; Mu, M. F. MRS Bulletin 2007, 32, 348.

(10) Mathur, R. B.; Pande, S.; Singh, B. P.; Dhami, T. L. Polymer Composites 2008, 29, 717.

(11) Luo, C.; Zuo, X.; Wang, L.; Wang, E.; Song, S.; Wang, J.; Wang, J.; Fan, C.; Cao, Y. Nano Letters 2008, 8, 4454.

(12) Ramasubramaniam, R.; Chen, J.; Liu, H. Y. Appl. Phys. Lett. 2003, 83, 2928.

(13) Sankapal, B. R.; Setyowati, K.; Chen, J.; Liu, H. Appl. Phys. Lett. 2007, 91173103.

(14) Ci, L.; Suhr, J.; Pushparaj, V.; Zhang, X.; Ajayan, P. M. Nano Letters 2008, 8, 2762.

(15) Worsley, M. A.; Satcher, J. H.; Baumann, T. F. Langmuir 2008, 24 , 9763.

(16) Byrne, M. T.; McNamee, W. P.; Gun'ko, Y. K. Nanotechnology, 2008, 415707.

(17) Tchoul, M. N.; Ford, W. T.; Ha, M. L. P.; Chavez-Sumarriva, I.; Grady, B. P.; Lolli, G.; Resasco, D. E.; Arepalli, S. Chem. Mater. 2008, 20, 3120.

(18) Islam, M. F.; Rojas, E.; Bergey, D. M.; Johnson, A. T.; Yodh, A. G. Nano Letters 2003, 3, 269.

(19) Regev, O.; El Kati, P. N. B.; Loos, J.; Koning, C. E. Adv. Mater. 2004, $16,248$.

(20) Dyke, C. A.; Tour, J. M. J. Phys. Chem. A 2004, 108, 11151.

(21) Rouse, J. H. Langmuir 2005, 21, 1055.

(22) Vaisman, L.; Marom, G.; Wagner, H. D. Adv. Funct. Mater. 2006, 16, 357.

(23) Grossiord, N.; Loos, J.; Regev, O.; Koning, C. E. Chem. Mater. 2006, $18,1089$.

(24) Nish, A.; Hwang, J. Y.; Doig, J.; Nicholas, R. J. Nature Nanotech. 2007, 2,640 .

(25) Grossiord, N.; Loos, J.; Laake, L. v.; Maugey, M.; Zakri, C.; Koning, C. E.; Hart, A. J. Adv. Funct. Mater. 2008, 18, 3226.

(26) Yang, Y.; Gupta, M. C.; Dudley, K. L. Nanotechnology 2007, 18, 345701.

(27) Chen, J.; Xue, C. H.; Ramasubramaniam, R.; Liu, H. Y. Carbon 2006 , 44, 2142.

(28) Worsley, M. A.; Kucheyev, S. O.; Satcher, J. H.; Hamza, A. V.; Baumann, T. F. Appl. Phys. Lett. 2009, 94, 073115.

(29) Wang, J.; Angnes, L.; Tobias, H.; Roesner, R. A.; Hong, K. C.; Glass, R. S.; Kong, F. M.; Pekala, R. W. Anal. Chem. 1993, 65, 2300.

(30) Pekala, R. W. J. Mater. Sci. 1989, 24, 3221.

(31) Halpin, J. C. J. Composite Mater. 1969, 3, 732.

(32) Thostenson, E. T.; Ren, Z. F.; Chou, T. W. b. Composites Sci. Tech. 2001, 61, 1899. 